\title{
A New Surgical Way to Face Postpartum Hemorrhage
}

\author{
Loutfi Guennoun Abdelmounaim', N. Biougnach'1, Barka Rabea², Harbil Driss ${ }^{3}$, Tmiri Adil ${ }^{4}$, \\ Lafkir Said 5
}

${ }^{1}$ Department of Obstetrics and Gynecology, Maternal \& Child Regional Center of Meknes, Mohammed V University, Rabat, Morocco ${ }^{2}$ Department of Obstetrics and Gynecology, Higher Institute of Nursing and Health Techniques, Meknes, Morocco

${ }^{3}$ Higher Institute of Nursing and Health Techniques, Rabat, Morocco

${ }^{4}$ The Maternal \& Child Regional Center of Meknes, Hassan II University, Casablanca, Morocco

${ }^{5}$ The Inter-Communal Medical Center of Meknes, Hassan II University, Casablanca, Morocco

Email: loutfimounaim@hotmail.com

How to cite this paper: Abdelmounaim, L.G., Biougnach, N., Rabea, B., Driss, H., Adil, T. and Said, L. (2020) A New Surgical Way to Face Postpartum Hemorrhage. Open Journal of Obstetrics and Gynecology, 10, 1147-1155.

https://doi.org/10.4236/ojog.2020.1090108

Received: July 13, 2020

Accepted: August 31, 2020

Published: Sepetmber 3, 2020

Copyright $\odot 2020$ by author(s) and Scientific Research Publishing Inc. This work is licensed under the Creative Commons Attribution International License (CC BY 4.0).

http://creativecommons.org/licenses/by/4.0/

\section{(c) (i) Open Access}

\begin{abstract}
Objective: We introduced two novel hemostatic techniques to achieve hemostasis for postpartum hemorrhage (PPH). The first one (A: Uterus Isthmic Plication) was a new uterine compression suture, which compresses the hysterotomy site. In a severe case, we further added vessel ligation suture after performing A-suture (B-combination suture: B-suture: A + Wide Lateral Uterine Vascular Ligation). Methods: Of $140 \mathrm{PPH}$ cases, 90 were with mild $\mathrm{PPH}$ and 40 were with severe PPH. Our policy was: perform A-suture to mild PPH and perform B (combination) to severe $\mathrm{PPH}$. Study was performed during 2018-2019. The primary endpoint to evaluate the efficacy of the procedures was preserving the uterus (no hysterectomy). Results: A-procedure, performed to 90 patients with mild $\mathrm{PPH}$, was effective to all 90 patients, with all preserving the uterus. B-procedure, performed 38 patients with severe PPH (excluding two patients with uterine rupture), was effective in 37 patients, with one having undergone hysterectomy due to coagulopathy. Conclusion: Uterus Isthmic Plication (A-procedure) and addition of Wide Lateral Uterine Vascular Ligation to procedure-A (B-procedure) achieved hemostasis in patients with PPH. Prospective study is necessary to confirm the present data.
\end{abstract}

\section{Keywords}

Postpartum: PPH, Hemorrhage, Surgical, Technique, Uterus, Plication, Vascular, Ligation, Hemostatic, Hematometry, Amenorrhea and Isthmocoele

\section{Introduction}

Postpartum hemorrhage (PPH) is defined as blood loss of $\geq 500 \mathrm{ml}$ after vaginal 
delivery or $\geq 1000 \mathrm{ml}$ after caesarean section. Major PPH can be divided into moderate at $1000-2000 \mathrm{ml}$ or severe at over $2000 \mathrm{ml}$. Severe PPH is also defined as a fall in hemoglobin of $\geq 40 \mathrm{~g} / \mathrm{l}$ or the need for transfusion of 4 or more units of red blood cells (RBC) [1]. Massive PPH has been described as bleeds of more than $2500 \mathrm{ml}$ and is associated with significant morbidity, even in resource-rich countries, including admission to high dependency and intensive care and emergency hysterectomy ( $6 \%-8 \%$ of cases) [2]. PPH is a major cause of maternal morbidity and mortality. Worldwide PPH accounts for at least $30 \%$ of all maternal deaths [3]. Death from PPH occurs in about 1 per 1000 deliveries in low-resource countries compared with 1 in 100,000 deliveries in higher-resource countries [4]. PPH is estimated to occur in between $1 \%$ and $5 \%$ of deliveries [1] [5], but incidence estimates vary by definition. Globally, Calvert et al. reported PPH prevalence at $10.8 \%$ (95\% CI: $9.6-12.1$ ) in a systematic review and meta-analysis, with wide regional variation ranging from $7.2 \%$ (95\% CI: 6.3 - 8.1) in Oceana to $25.7 \%$ (95\% CI: 13.9 - 39.7) in Africa [6]. In our article, we have 130 patients out of a total of 7705 deliveries with a rate of $1.7 \%$ compared to the rates described in the literature [1] [5] [7]. This kind of accident is one of the biggest emergencies in obstetrics that we can predict only in some specific cases, but usually, we are caught unaware. So to avoid a maternal, fetal or both disastrous evolution, we have to be able to act quickly and effectively, for these reasons we have developed two new surgical techniques.

\section{Surgical Management of PPH}

Failed medical and mechanical approaches to management of PPH warrant surgical exploration [8]. The surgical approach differs by delivery method, suspected etiology and clinical status [9]. The surgeon must decide if a laparotomy in case of vaginal delivery after a quick and a careful exploration of the lower genital tract or re-laparotomy after cesarean section, to identify the cause of PPH and make the decision of a conservative or a radical treatment. Placement of uterine compression sutures in a suspender fashion to promote uterine contractility may be a useful initial attempt at bleeding cessation while preserving fertility. Compression sutures should be used as a first step in surgical management when hemorrhage is a result of atony. The most described uterine compression sutures are B-Lynch procedure or Cho suture, carried out if a hysterotomy has been performed (delivery via cesarean section) and Hayman suture in the absence of a hysterotomy (vaginal delivery), is technically less challenging than vessel ligation and results in less morbidity than a hysterectomy [8]. Alternatively, the uterine or the internal iliac arteries can be ligated bilaterally to temporarily decrease blood perfusion to the uterus. While ligation of the internal iliac arteries was once more common, uterine artery ligation is now favored for ease of identification and higher success rates (80\% - 96\%) [10].

In the same purpose, we have elaborated two techniques, the first one can be considered as compressive suture, we called it "uterine isthmic plicature or 
A-Loutfi procedure" and the second technique is a wide lateral uterine vascular ligation named B-Loutfi procedure.

\section{-Uterine Isthmic Picture (Loutfi-A procedure).}

Description of the Uterine Isthmic Plicature (A-Loutfi procedure):

This technique consists of performing a large compressive suture, performed after doing the hysterorrhaphy. In fact, we use a delayed absorbable multifilament suture, that crosses the anterior uterine wall (out-in) from the upper side to the lower one of the right edge of the cesarean section scar, then we pull the multifilament to the other edge and we insert the curved needle from the lower side (out-in) to the upper side (in-out) of the left edge of the hysterorrhaphy by crossing the anterior uterine wall only, so as we don't affect the uterine cavity integrity. At the end we tie a knot at the middle of the superior part of the hysterorrhaphy as shown in Figure 1 and Picture 1. It helps so tightening the

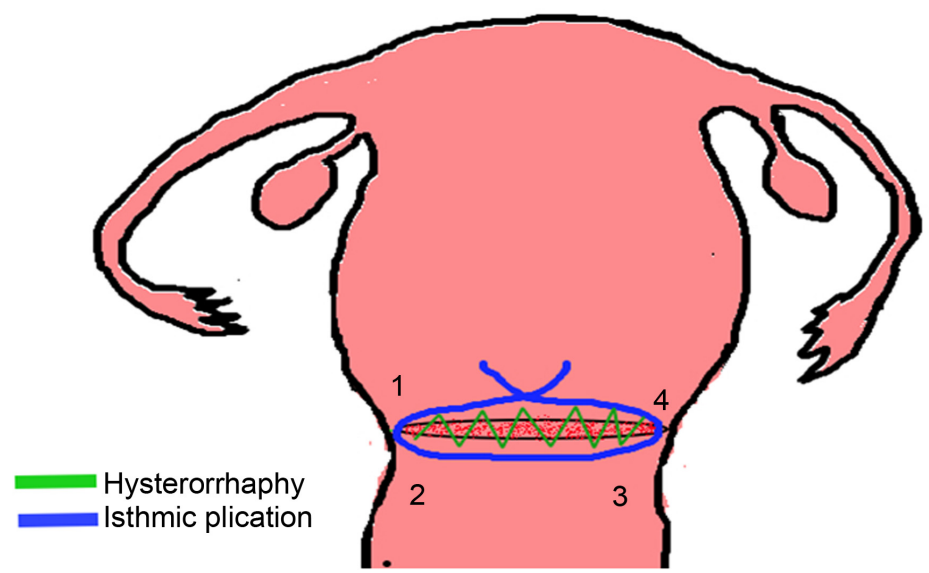

Figure 1. Diagram describing the first technique.

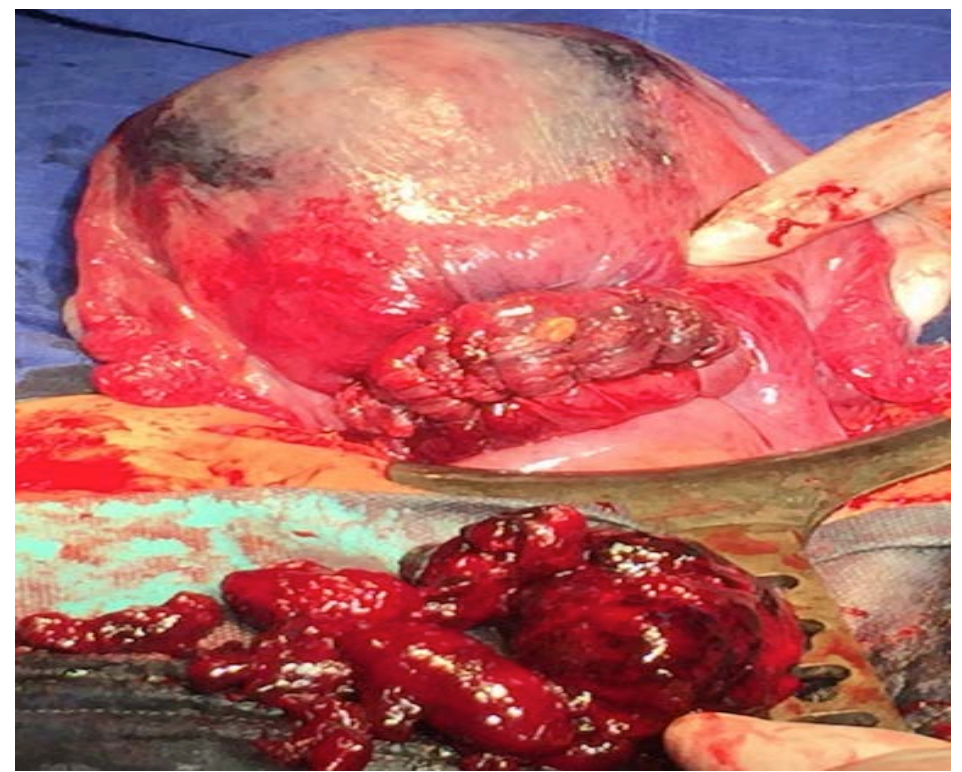

Picture 1. Photo showing the appearance of the uterus after performing the first technique. 
weakest part of the uterus: the lower segment. The weakness of this segment is due to its distention at the end of pregnancy. At the same time, this anterior uterus wall "tie" helps narrow the uterine arteries lumen by tracting both left and right uterine arteries medially and also it helps lifting the anterior wall of the uterus and at the same time narrowing the uterine cavity. The merit of this technique in comparison with other compressive suturing techniques as Cho's multiple square suture, B-Lynch "Brace" suture, Hayman suture, Matsubara-Yano suture and many others described in literature [11]-[19] is that: it preserves the integrity of the uterine cavity, it's easy to perform with an average time estimated at 3 minutes ( 4 - 5 minutes) and until the writing of this article we have not observed any complication at all. We usually decide to use this technique in moderate cases of postpartum hemorrhage and we are going to show in base of statistics its usefulness.

-Wide lateral uterine vascular ligation (B-Loutfi procedure).

Description of the wide lateral uterine vascular ligation.

(B-Loutfi procedure):

This procedure consists of performing a large vascular ligation. Technically, we begin by inserting the needle in the posterior face of the uterus $2 \mathrm{~cm}$ medially to the lateral border, $1 \mathrm{~cm}$ under the insertion of the utero-sacral ligament, after the needle crosses both layers of the uterus, we take it out anteriorly to join the upper part of the broad ligament just above the medial fallopian artery that we can identify by transparency, as shown in Figure 2 and Picture 2. The difference with other uterine vascular ligation is that we ligate in one suture: the uterine artery, the uterosacral ligament, the round ligament and all the lateral uterine vascular ramifications. With this large ligation we suppress widely the uterus blood affluence while preserving the Fallopian tube. All this in an average time of $5 \min (4-6 \mathrm{~min})$.

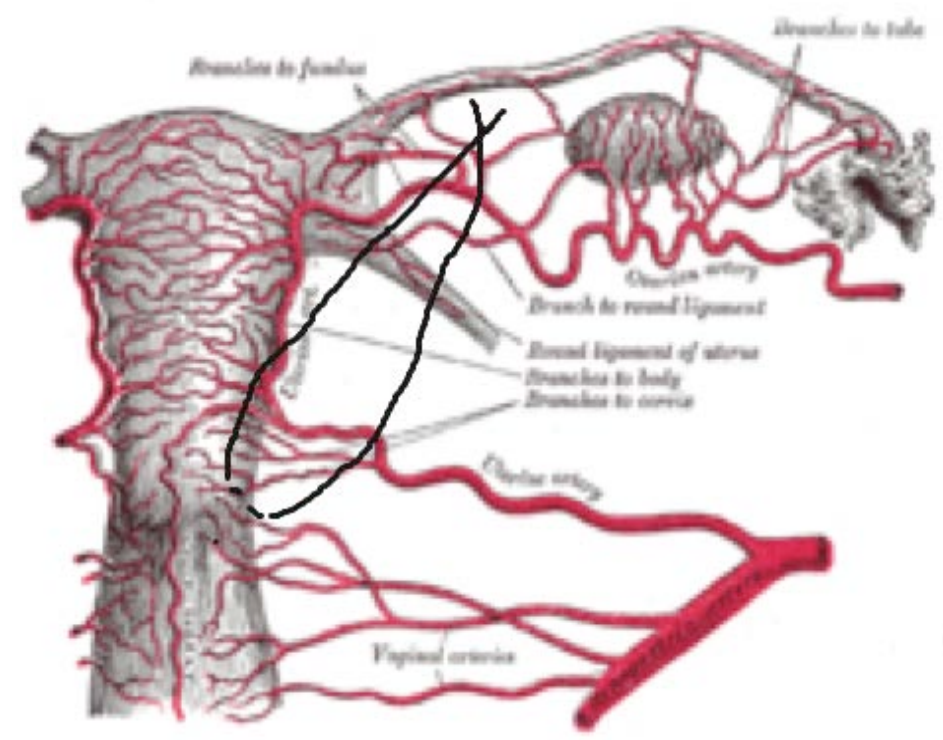

Figure 2. Diagram describing the 2nd technique. 


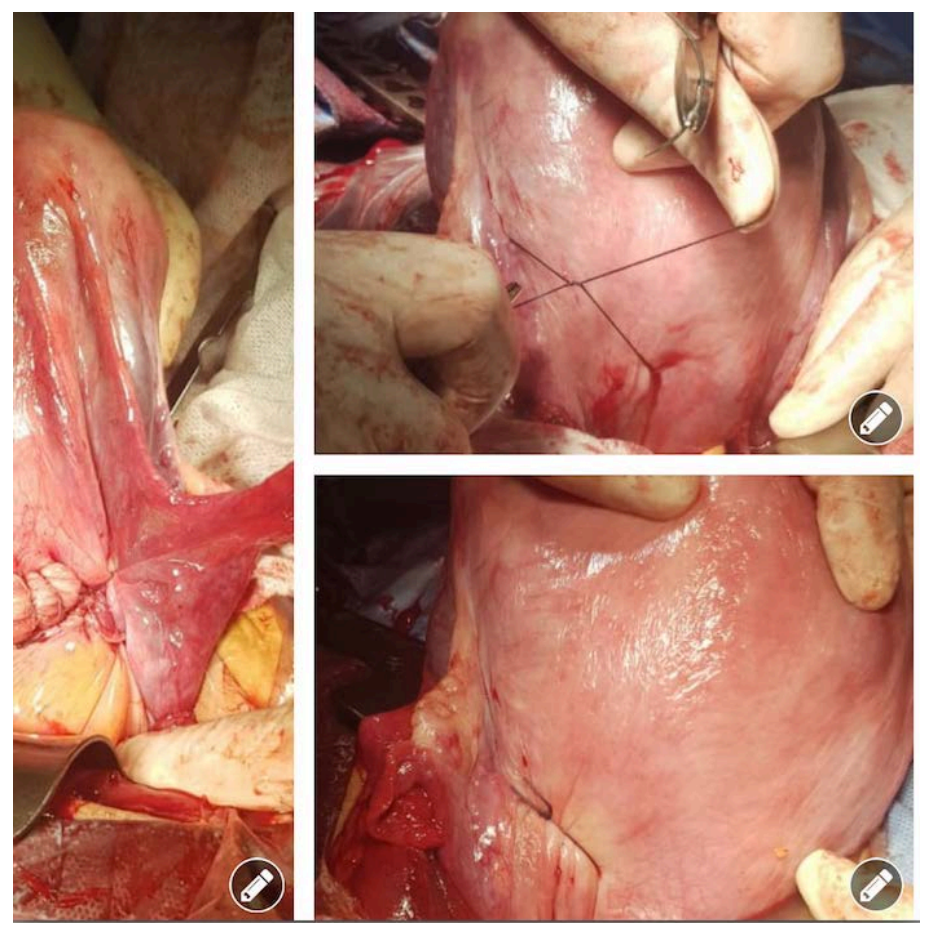

Picture 2. Assembly of 3 photos, showing the appearance of the uterus after the completion of the 2 nd technique.

Both techniques are easy to reproduce and to learn and can be a solution for the problem reported by Pierre-Emmanuel Bouet: "An alarmingly high number of French senior residents in Obstetrics and Gynecology report that they have not acquired the sufficient surgical skills during their training to be able to perform the surgeries required for the management of postpartum hemorrhage" [20].

\section{Results}

130 patients presented a postpartum hemorrhage treated surgically out of a total of 7705 patients that we delivered during a period of two years (2018-2019) with a rate of $1.7 \%$ comparable to literature [1] [5] [7] [21].

We separated our patients into two distinguished groups: A and B.

- Group A: we have performed the first technique on the 90/130 patients (69\%) with a hemodynamic stabilization and an immediate stop of hemorrhage. These patients have been followed for their pregnancies at our hospital and have been admitted from the beginning of their labor till they delivered. 70 patients $(54 \%)$ of this group delivered normally after what they presented uterus atony. 20 patients (15\%) did have a cesarean section, with 12 intervention for fetopelvic disproportion, 5 for fetal malposition and 3 operations for multiple pregnancies. The mean blood loss in the 70 patients that presented a secondary postpartum hemorrhage after delivering normally was $750 \mathrm{ml}(700$ - 800), with a hemoglobin average at $11 \mathrm{~g} / \mathrm{dl}(10-12 \mathrm{~g} / \mathrm{dl})$ and because the treatment was quick and efficient, we have been obliged to perform a blood 
transfusion in only 10 patients because their hemoglobin at admission ranged between 10 and $11 \mathrm{~g} / \mathrm{dl}$ ( 2 packed red blood cells). For the 20 patients who delivered by cesarean section in this A-Group, the hemoglobin average was $10.5 \mathrm{~g} / \mathrm{dl}(9.6$ - $11.4 \mathrm{~g} / \mathrm{dl})$. The blood loss ranged between $1.2 \mathrm{~L}$ to $2.3 \mathrm{~L}$ and we decided the success of the first technique on the basis of hemodynamic parameters stabilization. We decided blood transfusion in only 3 patients (multiple pregnancies, because of their hemoglobin at admission: 9 - $10 \mathrm{~g} / \mathrm{dl}$ ). We decided to transfuse 3 packed red blood cells.

- Group B: this group includes 40/130 patients (31\%), all these patients were transferred to us from other hospital structures because we are in a referral hospital. With 37 patients who benefited of the combination of the two techniques (A-Loutfi procedure and B-Loutfi procedure) as already mentioned above, because they arrived with a severe post partum hemorrhage, showing signs of hemorrhagic shock on admission and the first procedure has not been sufficient because of persistence of hemodynamic parameters instability, so we have been obliged after only 10 minutes to add the second procedure. Both techniques were efficient and stabilized the patients with no need to transfer them to the intensive care unit. But we must specify that we

Transfused 22 patients with 4 packed red blood cells and 4 fresh frozen plasma, because they have been admitted with signs of shock. In 15 patients we transfused 02 packed red blood cells and 2 fresh frozen plasma, because their intake hemoglobin ranged between $(6-8 \mathrm{~g} / \mathrm{dl}) .02$ patients were presenting clinical symptoms of uterine rupture on their arrival, confirmed when laparotomized and because they presented complicated cases of uterine rupture, we performed subtotal hysterectomy. The last patient was presenting on admission a disseminated intravascular coagulation, confirmed biologically later and in spite of performing the uterine isthmic plication combined to the wide lateral uterine vascular ligation we have been obliged to do the subtotal hysterectomy and transfer her to the intensive care where she benefited from transfusion of 07 packed red blood, 10 fresh frozen plasma, 10 concentrated platelets and the second day in intensive care unit she presented an acute renal failure, so she beneficiated from renal dialysis sessions.

\section{Discussion}

The results of our study allow us to note, that our conservative techniques helped saving life of $127 / 130$ (98\%) patients with uterus preservation, Concerning the 3 remaining patients, 2 of them were presenting complicated uterine rupture and the last one was presenting disseminated intravascular coagulation, so we have been obliged to perform a subtotal hysterectomy. Our rate is well ahead of other vascular ligation and uterine plication as reported in literature by J. B. Haumontéal and all [22]: "Conservative surgical treatment has a 70\% efficacy to stop hemorrhage whatever treatment used (vascular ligature or hemostatic brace suturing)" and Salvat Jilateral [23] who reported that, bilateral ligation 


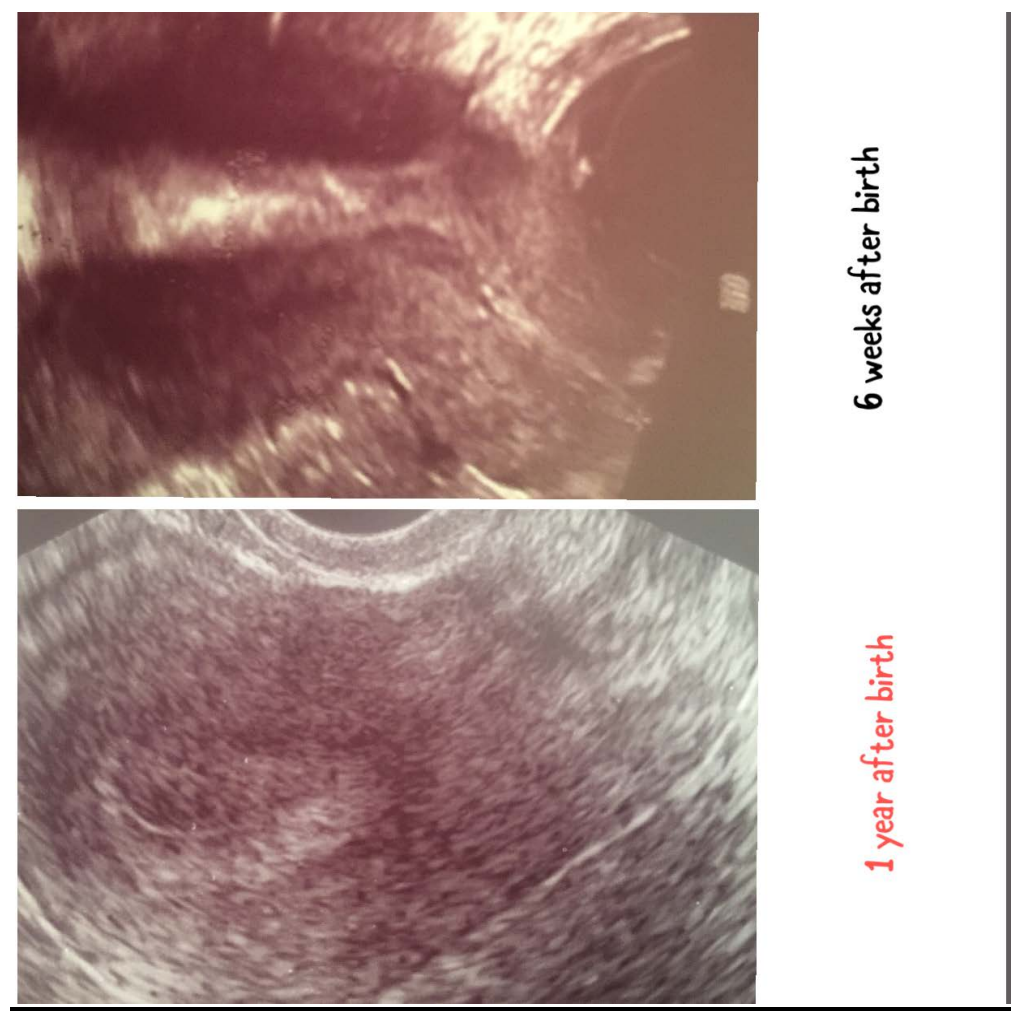

Picture 3. Two uterine vaginal ultrasounds showing the absence of isthmocele.

of the hypogastric artery can provide success in $66 \%$ of cases. Other articles reported rates less than our as Hüseyin Cengiz and all [24]: "Organ preserving surgery methods were utilized in all the patients with a success rate $78.9 \%$ ”. In addition to the absence of any of the complications described in literature [11]-[19], we noted during the follow-up, another benefit, which is the absence of isthmocoel in all patients with a median follow-up of 12 months, as shown in Picture 3.

\section{Conclusions}

We can conclude that with a success rate of $98 \%$ our easy techniques are indeed efficient, not expensive and not requiring large logistics. We can also add that with an average follow-up of 12 months, we haven't seen any of the usual complications expected in such techniques as: hematometry, amenorrhea, necrosis or dehiscence and even no isthmocoel. Another study is underway for a longer follow-up period.

We must emphasize that the management of postpartum hemorrhage is not only dependent on one or two surgical techniques, but above all, on a quick diagnosis, as well as a good responsiveness of the whole care team.

\section{Conflicts of Interest}

The authors declare no conflicts of interest regarding the publication of this paper. 


\section{References}

[1] Lu, M.C., Fridman, M., Korst, L.M., et al. (2005) Variations in the Incidence of Postpartum Hemorrhage across Hospitals in California. Maternal and Child Health Journal, 9, 297-306. https://doi.org/10.1007/s10995-005-0009-3

[2] Lennox, C.M.L. (2013) Scottish Confidential Audit of Severe Maternal Morbidity, 9th Annual Report (Data from 2011).

http://www.scottishpatientsafetyprogramme.scot.nhs.uk/Media/Docs/MCQIC/Mate rnity\%20Care/2013-08-09\%20Final\%209th\%20annual\%20SCASMM\%20report.pdf

[3] World Health Organisation (2012) Maternal Mortality: Fact Sheet 348. http://www.who.int/mediacentre/factsheets/fs348/en

[4] Carroli, G., Cuesta, C., Abalos, E. and Metin Gulmezoglu, A. (2008) Epidemiology of Postpartum Haemorrhage: A Systematic Review. Best Practice \& Research: Clinical Obstetrics \& Gynaecology, 22, 999-1012.

https://doi.org/10.1016/j.bpobgyn.2008.08.004

[5] Bateman, B.T., Berman, M.F., Riley, L.E. and Leffert, L.R. (2010) The Epidemiology of Postpartum Hemorrhage in a Large, Nationwide Sample of Deliveries. Anesthesia \& Analgesia, 110, 1368-1373. https://doi.org/10.1213/ANE.0b013e3181d74898

[6] Calvert, C., Thomas, S.L., Ronsmans, C., Wagner, K.S., Adler, A.J. and Filippi, V. (2012) Identifying Regional Variation in the Prevalence of Postpartum Haemorrhage: A Systematic Review and Meta-Analysis. PLoS ONE, 7, e41114. https://doi.org/10.1371/journal.pone.0041114

[7] World Health Organization (2012) WHO Handbook for Guideline Development. Geneva.

[8] American College of Obstetricians and Gynecologists (2006) ACOG Practice Bulletin: Clinical Management Guidelines for Obstetrician-Gynecologists Number 76, October 2006: Postpartum Hemorrhage. Obstetrics \& Gynecology, 108, 1039-1047. https://doi.org/10.1097/00006250-200610000-00046

[9] Walfish, M., Neuman, A. and Wlody, D. (2009) Maternal Haemorrhage. British Journal of Anaesthesia, 103, i47-i56. https://doi.org/10.1093/bja/aep303

[10] Rath, W., Hackethal, A. and Bohlmann, M.K. (2012) Second-Line Treatment of Postpartum Haemorrhage (PPH). Archives of Gynecology and Obstetrics, 286, 549-561. https://doi.org/10.1007/s00404-012-2329-Z

[11] Akoury, H. and Sherman, C. (2008) Uterine Wall Partial Thickness Necrosis Following Combined B-Lynch and Cho Square Sutures for the Treatment of Primary Postpartum Hemorrhage. Journal of Obstetrics and Gynaecology Canada, 30, 421-424. https://doi.org/10.1016/S1701-2163(16)32827-4

[12] Goojha, C.A., Case, A. and Pierson, R. (2010) Development of Asherman Syndrome after Conservative Surgical Management of Intractable Postpartum Hemorrhage. Fertility and Sterility, 94, 1098.e1-5. https://doi.org/10.1016/j.fertnstert.2010.01.078

[13] Gottlieb, A.G., Pandipati, S., Davis, K.M. and Gibbs, R.S. (2008) Uterine Necrosis: A Complication of Uterine Compression Sutures. Obstetrics \& Gynecology, 112, 429-431. https://doi.org/10.1097/AOG.0b013e31817b0781

[14] Jamard, A., Turck, M., Chéret-Benoist, A., Dreyfus, M. and Benoist, G. (2014) Risk of Uterine Synechiae Following Uterine Compression during Postpartum Hemorrhage. Gynécologie Obstétrique \& Fertilité, 42, 681-685. https://doi.org/10.1016/j.gyobfe.2014.04.013

[15] Mallappa Saroja, C.S., Nankani, A. and El-Hamamy, E. (2010) Uterine Compression Sutures, an Update: Review of Efficacy, Safety and Complications of B-Lynch Suture 
and Other Uterine Compression Techniques for Postpartum Hemorrhage. Archives of Gynecology and Obstetrics, 281, 581-588. https://doi.org/10.1007/s00404-009-1249-Z

[16] Marasinghe, J.P. and Saravanabhava, N. (2011) Risk of Synechiae Following Uterine Compression Sutures. BJOG, 118, 1020-1021. https://doi.org/10.1111/j.1471-0528.2011.03007.x

[17] Mishra, A., Dash, S. and Rath, S.K. (2019) B-Lynch Resulting in Total Uterine Necrosis Leading to Obstetric Hysterectomy. The Journal of Obstetrics and Gynecology of India, 69, 4-6. https://doi.org/10.1007/s13224-017-1068-2

[18] Simpson, A.N., Pittini, R., Hui, D., Morgan, A. and Kroft, J. (2015) Uterine Full Thickness Multifocal Dehiscence Associated with a History of Cho Uterine Compression Sutures. Journal of Obstetrics and Gynaecology Canada, 37, 583. https://doi.org/10.1016/S1701-2163(15)30192-4

[19] Suzuki, Y., Matsuzaki, S., Mimura, K., Kumasawa, K., Tomimatsu, T., Endo, M. and Kimura, T. (2017) Investigation of Perioperative Complications Associated with Use of Uterine Compression Sutures. International Journal of Gynecology \& Obstetrics, 139, 28-33. https://doi.org/10.1002/ijgo.12249

[20] Bouet, P.-E., Madar, H., Froeliger, A., et al. (2019) Surgical Treatment of Postpartum Haemorrhage: National Survey of French Residents of Obstetrics and Gynecology. BMC Pregnancy Childbirth, 19, Article No. 91. https://doi.org/10.1186/s12884-019-2237-3

[21] Zheng, J., Xiong, X., Ma, Q., Zhang, X. and Li, M. (2011) A New Uterine Compression Suture for Postpartum Haemorrhage with Atony. BJOG, 118, 370-374. https://doi.org/10.1111/j.1471-0528.2010.02809.x

[22] Haumonté, J.-B., et al. (2014) Prise en charge chirurgicale d'une hémorragie du postpartum Surgical treatment of postpartum hemorrhage. Journal de Gynécologie Obstétrique et Biologie de la reproduction, 43, 1083-1103. https://doi.org/10.1016/j.jgyn.2014.10.003

[23] Salvat, J., Schmidt, M.H., Guilbert, M. and Martino, A. (2002) Vascular Ligation for the Severe Obstetrical Hemorrhage: Review of Literature. The Journal de Gynécologie Obstétrique et Biologie de la Reproduction (Paris), 31, 629-639.

[24] Cengiz, H., Yaşar, L., Ekin, M., Kaya, C. and Karakaş, S. (2012) Management of Intractable Postpartum Haemorrhage in a Tertiary Center: A 5-Year Experience. $\mathrm{Ni}$ gerian Medical Journal, 53, 85-88. https://doi.org/10.4103/0300-1652.103548 